\title{
“CROWDFUNDING” EM POLÍTICAS PÚBLICAS: CIBERPARTICIPAÇÃO E ESPELHO REFERENCIAL À AGENDA POLÍTICA
}

\section{"CROWDFUNDING" IN PUBLIC POLICY: CYBERPARTICIPATION AND REFERENCE MIRROR TO POLITICAL AGENDA}

Iuri Bolesina ${ }^{1}$ Luciano Araújo Migliavacca

RESUMO: Sob a lógica da Constituição Federal brasileira de 1988 e através dos aportes da fenomenologia, intenta-se um estudo jurídico e crítico acerca da ciberparticipação, através dos instrumentos de crowdfunding, no reconhecimento do problema em políticas públicas e da formatação da agenda política. Assim, no primeiro item se realizou uma abordagem conceitual e crítica sobre o "problema" em políticas públicas e a sua inserção na agenda política. Em seguida, o estudo dedicou-se a elucidar o atual cenário da ciberparticipação política-pública e do e-gov no Brasil. Por fim, avaliou-se a possibilidade de utilizar-se as práticas e instrumentos de crowdfunding para o debate sobre o problema em políticas públicas e a formatação da agenda política, reforçando-se a ciberparticipação. Em conclusão, obtevese, em termos gerais, que a utilização das práticas de crowdfunding e ciberparticipação em políticas públicas, especialmente, na fase de definição do problema, fortalece os ditames constitucionais de cidadania ao mesmo tempo que confere uma plataforma referencial aos agentes políticas na formatação da agenda política.

PALAVRAS-CHAVE: Políticas Públicas. Direito. Ciberparticipação. Crowdfunding.

ABSTRACT: Under the logic of the Brazilian Federal Constitution of 1988 and through the contributions of phenomenology, it intends to be a legal and critical study of the

\footnotetext{
${ }^{1}$ Doutorando e Mestre em Direito pela Universidade de Santa Cruz do Sul - UNISC. Especialista em Direito Civil pela Faculdade Meridional - IMED. Integrante do Grupo de Pesquisa "Intersecções jurídicas entre o público e o privado", coordenado pelo Pós-Dr. Jorge Renato dos Reis, vinculado ao CNPq. Professor da Escola de Direito na Faculdade Meridional - IMED. Advogado. E-mail: iuribolesina @ gmail.com

${ }^{2}$ Doutorando do Programa de Pós-Graduação em Direito da Universidade Estácio de Sá - DINTER UNESA /IMED, em Direito Público e Evolução Social, vinculado à linha de pesquisa: Acesso à Justiça e Efetividade do Processo. Mestre em Direito - UNISC. Pós-graduado lato sensu em Direito Tributário - UPF. Professor de Direito Processual Civil - IMED. Coordenador da Escola de Direito da IMED. Advogado. Email: lucmig@imed.edu.br
} 
cyberparticipation through the crowdfunding instruments, the recognition of the problem in public policy and formatting of the political agenda. Thus, in the first item was held a conceptual approach and criticism of the "problem" in public policy and its inclusion on the political agenda. Then, the study set out to clarify the current situation of political-public cyberparticipation and e-government in Brazil. Finally, evaluated the possibility of using up the practices and crowdfunding instruments to the debate on the issue in public policy and the formatting of the political agenda, reinforcing the cyberparticipation. In conclusion it was obtained, in general terms, that the use of practices of crowdfunding and cyberparticipation in public policy, especially in the problem definition phase, strengthens the constitutional principles of citizenship at the same time conferring a reference platform for political agents in defining the political agenda.

KEY-WORDS: Public Policy. Law. Cyberparticipation. Crowdfunding.

\section{INTRODUÇÃO}

O estudo sobre políticas públicas no Brasil talvez represente um dos quais possui maior ascensão nas últimas décadas, muito em razão da conjugação de fatores jurídicos, políticos e sociais, como a atual Constituição, a formatação de um Estado Democrático e o empoderamento das camadas sociais mais fragilizadas por iniciativas dos governos LulaDilma, respectivamente, que conduziram ao fortalecimento da noção de cidadania, ao amadurecimento do (inter)agir político e ao desvelamento da noção de bens/interesses públicos não necessariamente/exclusivamente estatais.

Em razão da amplitude do tema políticas públicas é natural o aparecimento de estudos mais ou menos setorizados - ao estilo das segmentações realizadas pelos estudos fulcrados nos ciclos das políticas públicas, porém não equivalentes -. Seguindo esta lógica, a presente digressão acadêmica busca trabalhar com o "problema", a "decisão" e a "agenda política" no âmbito das políticas públicas, em uma análise crítica, a partir da qual intenta-se, propositivamente, ponderar uma alternativa paralela ao que se pode chamar de modo clássico de formatação da agenda política. Assim sendo, não se pretende substituir as práticas já existentes, mas sim, somar e eventualmente colaborar para o seu melhoramento.

Para tanto, no primeiro item deste texto o foco recairá especificamente sobre as questões que orbitam "problema", a "decisão" e a "agenda política" no âmbito das políticas 
públicas. É neste espaço que serão averiguadas algumas das críticas e das contribuições já tecidas acerca dos contextos que antecedem a decisão política que formata a agenda. Sem embargo, igualmente será trazido o conceito adotado de políticas públicas, considerando que tal definição tem impacto (in)direto na pesquisa.

No segundo momento, debruçar-se-á sobre a base da ideia a ser proposta, qual seja, a internet como nicho de participação política. Neste ínterim visar-se-á elucidar como essa perspectiva se conforma em uma via de dois sentidos: de um lado as noções de e-gov e de outro lado as noções de ciberparticipação. Também aqui é que serão verificadas, ainda que rapidamente, questões pontuais sobre a forma e os desafios à internet como espaço de ação política.

Por fim, a parte final é reservada para a proposição da ideia - alternativa e paralela ao modelo clássico de formatação da agenda política. Essa proposição se vale dos fundamentos do "crowdfunding" e aplica-os no cenário de decisão das políticas públicas. Concomitantemente, enlaçam-se as ideias de ciberparticipação à formação de um espelho referencial aos formatadores de políticas públicas, criando pelos resultados positivos e negativos das ações de crowdfunding.

\section{0 “PROBLEMA" EM POLÍTICAS PÚBLICAS}

Tornou-se recorrente nos Estados adjetivados ${ }^{3}$ como Democráticos de Direito os debates acerca de políticas públicas, notadamente quando miradas sob o enfoque de mecanismos de concretização da dignidade humana. Daí porque se diga que políticas públicas enquanto tema fático e teórico é objeto que não se restringe a uma área exclusiva e que demanda uma abordagem complexa, interdisciplinar e transversal (SCHMIDT; MENEGAZZI, 2010, p. 3124). Justamente por políticas públicas tratarem de inúmeras temáticas e absorverem diversos aspectos (políticos, jurídico, social, histórico, para ficar apenas nestes) é que acaba sendo assunto de todas as áreas do conhecimento.

Diante disso, é natural, portanto, que a expressão "políticas públicas" esteja orbitada por uma nebulosa (de tentativas) de conceitos e definições, que intentam ser mais ou menos taxativas e que fatalmente tendem a ser alvo de críticas e sugestões, como bem sublinhado e

\footnotetext{
3 A expressão "adjetivo" é uma explícita homenagem a ideia de Canotilho (2002, p. 25-40), utilizada em seu texto ao texto "O Estado Adjetivado e a Teoria da Constituição".
} 
inventariado por Marta Rodrigues (2010, p. 28-53). Não obstante, é possível ler, com certa segurança, a política pública como:

\begin{abstract}
una serie de decisiones o de acciones, intencionalmente coherentes, tomadas por diferentes actores, públicos y a veces no públicos - cuyos recursos, nexos institucionales e intereses varían - a fin de resolver de manera puntual un problema políticamente definido como colectivo. Este conjunto de decisiones y acciones da lugar a actos formales, con un grado de obligatoriedad variable, tendentes a modificar la conducta de grupos sociales que, se supone, originaron el problema colectivo a resolver (grupos-objetivo), en el interés de grupos sociales que padecen los efectos negativos del problema en cuestión (beneficiarios finales) (SUBIRATS $e t$ al, 2012, p. 38).
\end{abstract}

Note-se do conceito trazido que a ideia de políticas públicas é ampla e complexa, misturando atores, necessidades sociais, recursos e movimentos políticos, de modo que é um equívoco equivaler a noção de "política pública", com as noções de uma "ação" dentro da política pública e de "direito social”. Para ilustrar veja que uma parte do direito social à saúde no Brasil pode ser concretizado via medicina preventiva (através dos agentes de saúde ou médicos da família), a qual representa apenas uma ação dentro da política pública de saúde nacional (que é mais ampla e conjuga diversas ações).

A análise de políticas públicas, ou mais especificamente a análise do desenvolvimento de uma política pública, é objeto de diversas abordagens tipológicas, teóricas e metodológicas (DYE, 2009, p. 100; SCHMIDT, 2008, p. 2313/2325/2328). Aqueles que optam por fragmentá-la ${ }^{4}$, criando as conhecidas "fases" (processos) da política pública costumam dedicar-lhe um viés mais institucional e no qual indicam três elementos como passos exordiais para a formatação de uma política pública: a existência, a percepção e a inclusão na agenda política de um problema a ser enfrentado (SCHMIDT, 2008, p. 2316).

A "existência" e a "percepção" de um problema a ser solucionado diz respeito a uma necessidade e/ou a uma insatisfação pública (social e coletiva) não atendida ou insuficientemente atendida; enquanto a percepção nada mais é do que a visibilidade, o conhecimento, desse problema pelos agentes governamentais competentes para resolvê-lo. A

\footnotetext{
${ }^{4}$ A fragmentação da política pública em "estágios", apesar de ser didaticamente aceita, é objeto de críticas que sustentam que: a) a indicação de fases pode induzir ao erro, pois não necessariamente o desenrolar cronológico da política pública segue a ordem didaticamente estipulada; b) tal medida acaba forçando uma "coerência artificial" no ciclo da política pública; c) a perspectiva segmentária tem uma visão notavelmente de cima para baixo (top-down) desconsiderando parcialmente a lógica (bottom-up); d) a lógica cíclica não dedica efetiva atenção a possibilidade de ciclos simultâneos e/ou de ciclos incompletos (SUBIRATS et al, 2012, p. 49) e; e) o "ciclo" não reflete verdadeiramente o dinamismo, amplitude e complexibilidade de uma política pública (SCHIMIDT, 2008, p. 2315).
} 
percepção, contudo, é um momento anterior a sua (eventual) inclusão na agenda política (SUBIRATS, et al, 2012, p. 46). Pode-se dizer que é o momento em que o problema social é encaminhado para a avaliação de sua "pertinência" política para ser ou não absorvido pela agenda política. Em assim sendo, nem todo problema social irá se tornar um problema a ser tutelado por uma política pública, pois muitos deles, em um determinado momento, não terão espaço na agenda governamental - a qual é sempre menor do que os problemas sociais predispostos a nela ingressarem - (RODRIGUES, 2010, p. 47-48).

Por seu turno, "inclusão na agenda política"5 (agenda setting) é o momento em que o problema social é reconhecido politicamente como estrategicamente interessante para ser tratado por meio de uma política pública. É o momento imediatamente após ser filtrado, no qual o problema social é inserido na agenda política e se transforma num problema públicopolítico (public issue) que será objeto de atenção governamental (HOWLETT; RAMESH; PERL, 2013, p. 104).

Em uma frase, em tese, nos dois primeiros elementos (existência e percepção) o que se tem é um "problema social”, ao tempo que no terceiro elemento (inclusão na agenda política) tem-se um "problema público-político", ou seja: a definição do que é "problema público" que será objeto da atenção governamental e eventualmente tratado via política pública é eminentemente político, uma decisão política (SUBIRATS et al, 2012, p. 131). A questão sobressalente é: "Por que alguns problemas aparecem na agenda governamental como objetos de ação e outros não?” (HOWLETT; RAMESH; PERL, 2013, p. 103).

Uma perspectiva interessante ${ }^{6}$ ao questionamento é a de Kingdon (1995), a qual denominou como "Multiple Streams model" (no qual revisita o "Garbage Can model" (COHEN; MARCH; OLSEN, 1972, p. 1-25)). Inicialmente Kingdon (2005, p. 3) questiona "why some alternatives for choice are seriously considered while others are neglected"? Ato contínuo, assevera que sua ideia de correntes múltiplas (multiple streams) é composta por quatro elementos autônomos entre si, sendo eles: a corrente do problema (problem stream), a corrente das alternativas de solução (policy stream), a corrente política (political stream) e a janela de oportunidades (policy window) (KINGDON, 1995, p. 205-206). Para o autor, quando os três primeiros confluem e se encontram a janela de oportunidade se abre por um

\footnotetext{
${ }^{5}$ A agenda política corresponde ao "[...] elenco de problemas e assuntos que chamam a atenção do governo e dos cidadãos. Não se trata de um documento formal ou escrito, e sim do rol das questões relevantes debatidas pelos agentes públicos e sociais, com forte repercussão na opinião pública.” (SCHMIDT, 2008, p. 2316).

${ }^{6}$ Dentre outras que são bem inventariadas por Howlett; Ramesh; Perl (2013, p. 104-120).
} 
certo espaço de tempo (depois do qual irá se fechar) e é nesse ínterim que a decisão por incluir um item na agenda deverá ocorrer, pois, em não acontecendo, os envolvidos carecerão aguardar uma próxima e incerta oportunidade (CARRILLO, 2007, p. 21).

Essa lógica aponta, já nos momentos (pré)iniciais de uma política pública, a fluidez e o dinamismo que lhe são próprios, pois o sucesso de um item na agenda política dependeria não tanto da sua origem (enquanto problema social), mas muito mais do ambiente em que está sendo analisada (PINTO, 2008, p. 31), o qual deve catalisar positivamente variáveis como oportunidade, lideranças, tempo, recursos, interesses, expectativas, dentre outras, para que uma demanda seja reconhecida como problema público-político (RODRIGUES, 2010, p. 49). Essa visão, calcada na construção social do problema, supera a mirada objetivista acerca dos problemas sociais, a qual indicava que os problemas estavam todos prontos e predispostos a serem abordados pelos governos (como na lógica da garbage can) (HOWLETT; RAMESH; PERL, 2013, p. 103). É importante que se diga, aliás, que uma ou outra decisão, um ou outro comportamento, também dependerá do enfoque teórico (racionalismo, incrementalismo, escolha racional, sondagem mista, etc) que lhe foi dedicada(o) (ainda que implicitamente) nos momentos anteriores a decisão em si (ETZIONI, 2009, p. 233) 7.

Tal visão, entretanto, se foca, muito estritamente, no desenvolvimento institucionalformal da política pública, ou seja, estuda-se, de cima para baixo, como a decisão é/deveriaser tomada, sem focar no que se está/deveria-ser decidido - aspecto substancial (quem ganha o quê e por quê) (DYE, 2009, p. 105-106). Some-se a isso o fato de tal perspectiva conter uma incerta medida de fatalismo que repousa numa espécie de discricionariedade política da base majoritária. Tanto, Belmiro Castor (2009, p. 253/257) chamou de "nó górdio das teorias decisórias", asseverando que, no atual estado da arte em termos de decisão acerca do problema, remanesce na penumbra qualquer tentativa de estabelecerem-se regras que viabilizem controlar, bem como dar maior sinceridade e transparência às variáveis que são reveladas e as que ficam ocultas, por aquele que decide o que será um problema e como ele será enfrentado. Em suas palavras, afirma:

\footnotetext{
${ }^{7}$ Em pontual digressão aduz Schmidt (2008, p. 2316): “O número de situações problemáticas em um ambiente social é praticamente infinito. Mas, somente algumas delas tornam-se objeto de atenção da sociedade e do governo e entram na agenda política. [...] O fato de um governo não colocar um problema relevante na agenda política não se explica necessariamente pela falta de interesse dos governantes; é possível que não tenham força suficiente para fazê-lo ou que outras prioridades já definidas requeiram toda a energia política. Não se governa apenas com base na vontade".
} 
o nó górdio das teorias decisórias permanece na elevada carga de arbítrio (definido com o "resolução dependente só da vontade, ... opinião), que é exercitada pela tomador de decisões tanto na definição de um problema quanto na escolha das formas de enfrenta-lo. [...] A arbitrariedade começa pela própria definição do campo de investigação. [...] e a prevalência de uma dada interpretação é obviamente uma questão de poder dentro da organização. Por mais rebuscadas que sejam as teorias decisórias, por mais sofisticados que sejam seus arsenais de fórmulas e algoritmos, por mais democráticos que sejam os métodos de discussão, é preciso lembrar que uma decisão é essencialmente um ato de arbítrio por parte de alguém (ou de um grupo) que se julga capaz de exercitar o poder. Como escolher os valores que guiarão a interpretação de um determinado problema e a escolha das alternativas para sua solução? (CASTOR, 2009, p. 254).

A crítica tecida não se dá tanto na dinâmica de reconhecimento do problema públicopolítico - ao fato de que a construção da agenda política, através da tomada de decisões e de não-decisões (DYE, 2008, p. 38), ocorre por meio de movimentos de avanços e retrocessos, no âmago de um quadro social, político e histórico complexo, que faz com que interesses e problemas entrem em processo de concorrência, ao fim da qual o problema que obteve maior apoio (pelas razões que forem) será o eleito à ocupar lugar nas preocupações governamentais - (SUBIRATS et al, 2012, p. 147); a crítica reside muito mais no reconhecimento em si, notadamente porque não é habitual que as decisões políticas revelem, com dados aferíveis e controláveis, porque um problema é mais importante que outro e quais foram os fatores que conduziram a eleger/incluir um problema e não outro, assim como não se pode aceitar que a decisão política ocorra somente pela (boa/má) vontade política ou por pressões/interesses circunstanciais.

Ademais, é preciso reconhecer, na esteira do que propõe Dye (2008, p. 32-33) que: a) a agenda não "simplesmente acontece", pois ela é o elo final de uma corrente de acontecimentos estratégicos, nem sempre visíveis, das pessoas e dos grupos envolvidos/interessados, de modo que deveria haver reciprocidade entre a energia empenhada na concorrência pela atenção governamental e a energia utilizada na justificação pela eleição/inclusão de um problema na agenda política; b) quem decide o quê e o que e como é decidido é crucial para o processo de formulação de políticas: "deciding what will be the problems is even more important than deciding what will be the solutions" (DYE, 2008, p. 32).

Em assim sendo, dois pontos são destacáveis: (1) como dar visibilidade a um problema social, a fim de influir efetivamente no momento da decisão política e (2) como controlar a 
decisão que incluiu um item na agenda política ao invés de outro. Este estudo, dada a amplitude dos pontos, a partir de agora de focará no primeiro deles, exclusivamente.

\section{A INTERNET COMO NICHO DE PARTICIPAÇÃO POLÍTICA: UMA VIA DE DOIS SENTIDOS (E-GOV E CIBERPARTICIPAÇÃO)}

As TICs (tecnologias da informação e da comunicação), dentre as quais está a internet, quando inseridas no espaço político representam uma via de mão dupla: em um sentido visam inovar no governo eletrônico e apoiar-se nessas ferramentas para revitalizar o setor público da administração, da representação e da gestão; e, em outro sentido, intentam melhorar o acesso e o uso dessas tecnologias pelos cidadãos, ao mesmo tempo que buscam fomentar a participação democrática e cidadã nos assuntos públicos (LEMOS; LÉVY, 2012, p. 138-139). Em um sentido mais amplo essas duas vias podem representar a ideia de Democracia Digital ${ }^{8}$

O uso das TICs para fins de governança tem recebido o nome de "E-gov" ou "governo eletrônico", nome que tenta conjugar os elementos do digital e do virtual, do online e do offline. O E-gov é atualmente lido ao lado da "E-Administração" e da "E-democracia", sendo visto sob as luzes do "Government 2.0" (iniciado nos Estados Unidos, ao longo da primeira eleição do Presidente Obama), veiculando a governança informacional, a qual trata da disponibilização, por vezes facilitada, descentralizada e horizontal, da informação (open data), de serviços e de vias de participação e cooperação cidadã, a partir do Estado, no objetivo de tornar mais eficazes às ações governamentais e relacionar reciprocamente e qualitativamente suas ações com os governados (RIBEIRO; ANDRADE, 2005, p. 7).

$\mathrm{O}$ uso das TICs por parte da governança serve para "hacer mejor las cosas que ya hacen y para realizar cosas nuevas" (SÁNCHES, 2007, p. 142). Por parte do Estado, é comum referir que o E-gov leva os méritos de: a) facilitar o exercício da accountability política; b) aumentar e melhorar a disponibilização de informações; c) fortalecer a eficácia e a

\footnotetext{
8 'A 'democracia digital' (e outros verbetes concorrentes) é, neste sentido, um expediente semântico empregado para referir-se à experiência da internet e de dispositivos que lhe são compatíveis, todos eles voltados para o incremento das potencialidades de participação civil na condução dos negócios públicos. [...] A democracia digital se apresenta como uma alternativa para a implementação de uma nova experiência democrática fundada numa nova noção de democracia" (GOMES, 2005, pág. 217-218).

9 Vale referenciar os três grandes eixos da linhagem "E", sendo eles: a "e-administração", o "e-gov" e a "edemocracia". Esses três eixos, apesar de muito próximos são conceitos diferentes com conteúdo diversos (ARAÚJO; MAIA, 2014, p. 85). No presente texto a expressão "e-gov" englobará a "e-administração" e estará sempre conectada a "e-democracia".
} 
eficiência da administração dos Poderes, dos funcionários públicos e dos representantes políticos; d) reduzir os custos na administração e para a participação popular (HEMANY; FRANTZ, 2010, p. 3238-3239); e) democratizar a administração em sentido amplo e; f) criar novas formas de participação política (BRUGUÉ; GALLEGO, 2007, p. 45-51).

Em solo brasileiro, a iniciativa "Gov.br", do Ministério do Planejamento, Orçamento e Gestão, se fomenta o uso das TICs atuando em três frentes, sendo elas: 1) Junto ao cidadão; 2) $\mathrm{Na}$ melhoria da sua própria gestão interna e; 3) Na integração com parceiros e fornecedores. Os objetivos centrais são promover a cidadania, aumentar e qualificar os níveis de inclusão digital, valorizar os softwares livres, privilegiar a gestão do conhecimento, racionalizar o uso de recursos e formatar o arcabouço integrativo de ações do governo em todos os níveis, bem como de políticas, sistemas e padrões (MINISTÉRIO DO PLANEJAMENTO, ORÇAMENTO E GESTÃO, s/d).

São exemplos de práticas realizadas pelo governo federal brasileiro os portais do "acesso à informação" e da "transparência", bem como e mais incisivamente o "edemocracia: participação virtual, cidadania real" ambiente virtual do Legislativo Federal no qual se criam sites, links, fóruns, salas de chat, elaboram-se enquetes, disponibilizam-se biblioteca virtual e, mais interessantemente, oportuniza-se o Wikilegis (no qual o cidadão pode tecer comentários sobre o projeto de lei ou sobre seus artigos, bem como adicionar ideias). Através do portal do "e-democracia" - apenas para se mensurar o nível de participação e os interessantes resultados via democracia digital - o Estatuto da Juventude teve cerca de um terço do conteúdo do seu relatório final iluminado pela opinião dos próprios cidadãos; no debate sobre o Marco Civil da Internet, ao menos 10 sugestões dos usuários da plataforma foram aproveitadas; mais incisivamente, a LDO de 2013 contou com mais de 44 mil acessos, 551 contribuições efetivas e uma das enquetes online mais votadas no site (AUGUSTO, 2014, p. 18-20).

Por seu turno, em âmbito internacional, as iniciativas de e-gov são inúmeras e em níveis de sucesso diferenciados, sendo inclusive hercúleo mapeá-las. O que chama atenção, contudo, são os laboratórios de inovação à cibergovernança, que são locais em que a pesquisa é voltada para o desenvolvimento de mecanismos inovadores para os desafios da administração e da política estatal, não apenas com o intuito de visar a solução aos problemas, mas igualmente no sentido de se criar redes de trabalho e parcerias. Neste espaço, apenas para ilustrar, estão a Innovate SF, a Public Policy Lab (Estados Unidos), a Silk, a OPM Innovation 
Lab (Reino Unido), a Mindlab (Dinamarca) e a DesignGov (Austrália) (PARSONS DESIS LAB, 2013).

Já, por parte da população em geral o uso das NITs acaba representando: a) uma forma de empoderamento social e político; b) a facilitação do acesso à informação pública e ao conhecimento institucional; c) a melhora na participação, cogestão e cooperação nas questões públicas manejadas primordialmente pelo Estado; d) simplificação, pelo menos em tese, do contato com os representantes políticos e; e) o convite a ciberparticipação e ao ciberativismo político (SÁNCHES, 2007, p. 144-145).

Em termos de participação na democracia digital, Wilson Gomes (2005, p. 218-220) realiza uma classificação em cinco graus escalonados de participação civil nos assuntos públicos via e-gov, sendo que o mais alto nível corresponderia à práticas totalmente inseridas nas lógicas da democracia digital. Para o autor, da base para o topo da escala, os níveis seriam os seguintes: $1^{\circ}$ ) cidadania delivery; $2^{\circ}$ ) cidadania de consulta/porosidade; $3^{\circ}$ ) democracia de transparência; $4^{\circ}$ ) democracia Deliberativa e; $5^{\circ}$ ) Democracia direta plug and play. Adverte o autor que, em geral, os Estados movem-se confortavelmente nos dois primeiros graus, sendo que não há realizações concretas em relação ao último grau.

As tendências contemporâneas do E-gov sinalizam uma mudança ocasionada pelo "modo de ser" fomentado pela Internet: sai-se da democracia eletrônica participativa/deliberativa e ruma-se para uma democracia eletrônica cooperativa: antes de responder sobre o local que desejam o novo aeroporto os internautas-cidadãos preferem debater se há necessidade de um novo aeroporto. É, efetivamente, uma das faces da ciberparticipação política que foi alimentada pelo E-gov, notadamente pelos novos mecanismos e pelos novos canais de acesso aos setores públicos outrora dominados e enclausurados nos labirintos do Estado e de seus agentes.

Tal perspectiva colaborativa vem fortemente acompanhada de uma revisão do pacto de "bem estar social" e político firmado entre os representantes e os representados: diminui-se consideravelmente o abismo entre essas duas categorias, esfacela-se a lógica de participação política débil, passiva e muitas vezes subserviente como moeda de troca de serviços e políticas públicas e constroem-se, no clarear do século XXI, expectativas legitimas de participação, cooperação, diálogo e negociação no acontecer dos serviços e políticas públicas, em um Estado transparente e, realmente, democrático (BRUGUÉ; GALLEGO, 2007, p. 58). 
Essa lógica cooperativa se apropria do trinômio possibilidade/interesse/oportunidade, no sentido de que os ciberparticipantes, sempre que possível e quando lhes interessar, valerse-ão das oportunidades oferecidas pelo e-gov. Um bom exemplo disso, aliás, de baixo custo, é trazido por Lemos e Lévy (2012, p. 141) ao mencionarem o americano "Govt.com" que em sinergia com o aplicativo "Our Town", criado por uma empresa privada, viabiliza um contato direito entre os cidadãos e a prefeitura local, para alertar sobre problemas da cidade (como um buraco na pista), questionar ações dos agentes públicos, lançar uma petição, solicitar serviços, consultar calendários e agendas públicas dos representantes políticos, dentre outras funcionalidades. Ademais, o trinômio da visão cooperativa se dá, nas palavras do sociólogo Dominique Cardon (2012, p. 86/87), porque:

\begin{abstract}
os internautas raramente debatem por encomenda. A maneira pela qual se apropriam de informações para criar controvérsias e organizar mobilizações permanece frequentemente imprevisível. Essa fabricação "por baixo" das coletividades torna difícil e pouco eficaz a implementação de dispositivos de consulta online inspirados nas lógicas da democracia participativa. As formas de deliberação cidadã iniciadas pelas instituições públicas na tela se revelaram decepcionantes. Conseguiram apenas mobilizar uma fração mínima de cidadãos muito envolvidos. [...] A demanda de participação se concebe mais frequentemente com uma experiência que se organiza em torno de um dispositivo que permite a ação e a cooperação. Muito mais flexível e autônoma, esta forma de participação não visa a entrar nos debates promovidos pelas instituições, mas sim organizar zonas especializadas ou de discussão fora do alcance das instituições. Em alguns casos indo contra seus princípios. Ao contrário das instituições, essa participação não procura iniciar ou conduzir o debate, encarregando-se somente de tornar mais fáceis as condições para que os internautas criem seus próprios debates.
\end{abstract}

Portanto, uma grande lição que tira das práticas de e-gov até o momento é que não se deve ter a pretensão de criá-las para fins torna-las obrigatórias aos usuários que se destina. Se assim for, sua existência será questionada e muito possivelmente terá receptividade baixa. Os meios proporcionados pelo e-gov devem, portanto figurar como formas alternativas e serem constantemente fomentados, não tentando impor ao usuário um padrão ou um conjunto de princípios advindos do Estado.

Outro fator que deve ser vencido para que as práticas de e-gov e para que a participação política online ganhe efetiva força é o próprio acesso a essas ferramentas. Dados de 2008, fornecidos pelo Miniwatts Marketing Group, revelam que apenas 22,6\% da população sul-americana possui acesso doméstico à internet, sendo que no Brasil estima-se que apenas $22,4 \%$ de toda a população possui internet com acesso doméstico (FRAGOSO; 
MALDONADO, 2009, p. 14-15). Números de 2013 demonstram que o total de pessoas com acesso doméstico à internet alcança a casa dos 40\% da população brasileira (IBOPE, 2013), sendo que deste percentual mais da metade, 54\%, acessa via telefone celular devido aos baixos custos dos planos (INFO, 2013). Os números da CETIC (Centro de Estudos sobre Tecnologia da Informação e da Comunicação) são muito próximos (CETIC, 2013a) e, em relação ao uso do E-gov pela população, a última pesquisa aponta que $68 \%$ da população brasileira, com acesso à internet, utiliza os serviços de E-gov (CETIC, 2013b). Ao lado dessa questão, somam-se os problemas de educação e conhecimento para o uso dessas tecnologias.

Não obstante, a continuidade do movimento de interconexão é uma tendência (LEMOS; LÉVY, 2012, p. 184), o qual acaba por acelerar e tornar corriqueiras para as futuras gerações as práticas online de comunicação, troca de conhecimentos, ações individuais e coletivas vinculadas à criatividade e ao empreendedorismo, compartilhamento de memória e percepção, bem como de interação com as próprias tecnologias de modo usual e integrado a incontáveis ferramentas.

\section{3 “CROWDFUNDING" EM POLÍTICAS PÚBLICAS: CIBERPARTICIPAÇÃO E ESPELHO REFERENCIAL}

A web, notadamente aquelas que representam um avanço em relação à proposta original - e que vem sendo denominadas como Web "2.0" (Youtube, Wikipedia, Blogs) e Web "3.0" (Twitter, Facebook, Instagran) - tem o poder de transformar o ideal de "comunicar mais, melhor e mais rápido" numa verdadeira revolução do modo de viver em sociedade, ao proporcionar o rompimento de lógicas clássicas das mais diversas áreas como comunicação, política e direito.

Não à toa, a internet é considerada um espaço neutro, sendo lhe impossível adjetivar algum inconsciente político, máxime em razão das possibilidades que proporciona na base das práticas democráticas que, até então, eram fortemente marcadas pela dualidade entre representante e representados, nos âmbitos da deliberação, organização, colaboração, socialização e da própria cidadania em sentido amplo (CARDON, 2012, p. 1). É justamente em virtude dessa miscelânea de razões e crenças sociopolíticas em um ambiente de rede neutro que contemporaneamente é possível pensar o exercício da cidadania e de práticas democráticas em ambientes políticos por meio da internet. 
Apesar de parecer um paradoxo conjugar a web e a política, uma vez que a primeira tem uma lógica de descentralização e desconcentração de poder, ao passo que a segunda, em sentido inverso, trabalha com a perspectiva de centralização e concentração do poder (ASCAVA, 2014, p. 1), o norte das propostas tem sido muito mais a participação política, as ações cidadãs e o reforço à democracia do que, explicitamente, movimentos de cunho político-partidário ou de (in)gerência direta no governo. Nesta trilha é que se pretende, a partir de agora, sugerir uma alternativa paralela ao processo clássico de decisão da agenda política, que consiste em um instrumento de ciberparticipação baseado nas práticas de crowdfunding que auxilie na definição de problemas para a agenda política. Vale sublinhar, a sugestão não visa substituir as práticas já existentes, mas sim, somar e eventualmente colaborar para o melhoramento da democracia e da cidadania através da internet.

De outro lado, a proposta calca-se sobre os apontamentos dos G8 Government on-line, que traça seis níveis de participação cidadã na rede que devem ser progressivamente satisfeitos pelos governos: a) acesso a informação governamental; b) interação online com o governos em relação aos serviços; c) discussão online entre cidadãos sobre temas de interesse público; d) discussão online com especialistas sobre temas de interesse público; e) discussão online com os representantes políticos; e f) contribuição de ideias relativas a questões de responsabilidade, primeiramente, governamental (SÁNCHES, 2007, p. 151). Ainda, tem inspiração nas linhas apontadas pelo Laboratório de Governança de Nova York (que desenvolve mecanismos para repensar as instituições democráticas no séculos XXI), que indica como mudanças a serem fortalecidas pelos governos: 1) a colaboração, co-criação e soluções coletivas ao invés de deliberação pura e simples; 2) descentralização das decisões no lugar de centralização; 3) abertura dos dados ao invés de fechamento das informações; 4) governos como plataformas de participação cidadã continua e não como prestadores de serviços (ASCAVA, 2014, p. 2).

Uma lógica "crowdfunding" pode ser tida como um espaço, uma iniciativa, onde pessoas ou grupos que possuem ideias, mas que não possuem força ou recursos suficientes para executar essas ideias, podem expô-las e, a partir disso, dialogar e receber contribuições de cunho intelectual e financeiro (sob a bandeira do all or nothing), a fim de melhorar e concretizar suas ideias originais. Contemporaneamente, existem sites especializados neste tipo de prática, como é o caso "Kickstarter" (tal qual a de sites similares como IndieGoGo, RocketHub e GoFundMe). 
O "Kickstarter", inspirando-se (também) na célebre frase de Henry Thoreau que diz "the world is but a canvas to our imagination" proporciona aos seus usuários uma plataforma de "crowdfunding" e, para sustentar essa perspectiva, resgata o ideal original de não segmentação hierárquica ou classista entre pessoa e de solidariedade na internet. Assim é que a plataforma "Kickstarter" acaba não só sendo um meio de arrecadação de dinheiro (a qual, aliás, já veiculou mais de 1 bilhão de dólares em projetos que vão de cartões postais caseiros à documentários ganhadores de prêmios), mas principalmente um local que possibilita a construção e aproximação de comunidades de pessoas que, trabalhando conjuntamente, interagem criando, criticado, melhorando, debatendo e/ou apoiando.

Ademais, em termos de acessibilidade e movimentação virtual, os sites de crowdfunding são aptos a empoderar o "pressuposto de igualdade" da internet, ao viabilizar que ideias particulares, muitas vezes sobre interesses públicos ou coletivos, ganhem visibilidade não pelo seu proponente (pelos seu espectro social, cultural, títulos e/ou qualificações acadêmicas), mas sim pelo mérito substancial da proposta. Para tanto, esses sites contam com canais que oferecem e facilitam o trânsito de informações, bem como com canais que estimulam a participação recíproca, consciente e corresponsável.

Mas e como essa lógica de crowdfunding pode auxiliar em políticas públicas? Ou, mais especificamente em relação ao tema proposto: como o crowdfunding pode auxiliar na definição de problemas para a agenda política? A internet, graças a sua descentralização, cria incontáveis movimentos capilares advindos da sua periferia, criando redes sutis e surpreendentes em termos de inovação (CARDON, 2012, p. 71). Se há uma frase que pode definir o comportamento criativo $d a$ internet é: “ok, internet... hoje você conseguiu me surpreender, de novo!". Então, por que não se valer dessa criatividade para o enfrentamento de questões sociopolíticas?

De início, é reiterável que os sites e as práticas de Crowdfunding, possuem o mérito de reunir em si os quatro eixos - oferecer informações, oferecer serviços, facilitar a participação e o acesso e fomentar a cidadania ativa - que Sánchez (2007, p. 144), no âmbito político, aponta como funções das nova tecnologias já absorvidas pelo Estado, isso é, práticas que as administrações (do Legislativo, do Executivo e do Judiciário) estão progressivamente concretizando. Em outros termos, significa dizer, que a implementação de uma ação de Crowdfunding voltada para políticas públicas, apesar de ser uma abordagem pioneira, não 
seria desgastante, no sentido de demandar inovações nunca antes tentadas ou recursos ainda não calculados.

Diante disso, crowdfunding em políticas públicas poderia ser executado com a criação de um software e de uma plataforma virtual, em que qualquer pessoa, grupo de pessoas ou organização poderia sugerir políticas públicas (tanto a ideia, quanto a sua inteira estrutura) de forma voluntária (já que as experiências virtuais governamentais que contavam com certo nível de imposição mostraram-se ineficazes). Nesta plataforma, a exemplo do que ocorre nos sites de crowdfunding, existiria um formulário de submissão a ser preenchido apontando, além dos dados do proponente, o problema a ser enfrentado, a esfera federativa do problema (local, estadual, federal), as pessoas/grupos envolvidas (grupo-objetivo, beneficiários finais, terceiros, apoiadores públicos e privados) e recursos (SUBIRATS et al, 2012, p. 59-65/73) já angariados, bem como, opcionalmente (pois esses itens requerem certos conhecimentos técnicos), sugerir o fluxo, a estrutura e os planos de ação, metas e objetivos da política pública.

Uma vez submetida a proposta, esta é publicizada em um mural. Neste mural, outras pessoas podem ler a ideia e "apoiar" ou "não apoiar" e, inclusive, dedicar um "apoio especial" - que consistiria em comprometer-se com efetivo auxílio: doações de recursos, trabalho voluntário, cessão de espaços, infraestrutura, aparelhamento, etc. - ou sugerir uma "moderação", a fim de filtrar eventuais ilegalidades ou irracionalidades da proposta. Essa moderação, seguindo o espírito libertário e neutro da web, seria sempre posterior à publicação (soft open publishing) - como ocorre em sites como o Agoravox, o Kuro5hin e o Slashdot (CARDON, 2012, p. 35-36). Ao lado destas possibilidades, cada proposta teria um fórum, dividido por tópicos, para discussões sobre a proposta, de modo que a além da proposta original existiriam sugestões e críticas a ela.

A partir deste ponto, duas possibilidade se abrem: 1) a primeira no sentido de não atribuir caráter vinculativo aos poderes representativos. Assim as propostas com maior número de apoiadores teriam maior "visibilidade" (estariam no topo/capa do site) e serviriam com uma espécie de espelho para os poderes representativos na formatação de sua agenda política. Como referido, essa via não teria caráter vinculativo, mas meramente referencial e reflexivo, uma vez que não seria razoável que os formuladores de políticas públicas estivessem a mercê de lobbys particularistas ou mesmo de propostas tendentes a afetar setores estratégicos para o Estado; 2) uma segunda possibilidade é que se atribuísse caráter 
vinculativo tão somente no que diz respeito à análise (e não na concretização) das propostas que atingissem um número considerável ou suficiente de apoiadores. Logo, a proposta deveria ser encaminhada aos poderes Legislativo e Executivo para que a avaliassem, a fim de (a) ou intentem projeto de lei ou (b) verificam a possibilidade de reconhecer e trabalhar com a proposta em outras políticas públicas já existentes ou (c) de rejeitá-la fundamentadamente. A fundamentação da rejeição ganha destaque quando se pensa que respostas dignas estimulam a participação, prestigiam o entendimento e facilitam o consenso.

Os projetos rejeitados e os projetos que não atingissem número considerável ou suficiente, permaneceriam no site, porém em espaço diverso, em um banco de propostas, no qual quedariam aguardando eventual concretização através da iniciativa particular, ou mesmo pelo Estado, em momento posterior, ou ainda, seu arquivamento pelo proponente ou pela inatividade no âmbito da proposta.

Práticas similares a então proposta já foram intentadas com níveis de sucesso diferentes. Sánches (2007, p. 146-148) apresenta exemplos como os sites MN E-Democracy, o E-thepeople e o Move on (Estados Unidos), o You Say (Reino Unido), o E-Petitioner (Escócia) e o Democracia.web (Espanha). As oportunidades que estes sites oferecem, apesar de não serem efetivamente crowdfundings intentam algo muito próximo que é a participação política e cidadã através da internet: é o que se tem chamado de crescente da ciberparticipação política (cuja uma das matizes é o ciberativismo):

el crecimiento del uso de Internet tiene como consecuencia inmediata la realización en la red de iniciativas ciudadanas de todo tipo. A pesar de que la política no sea un ámbito seguido mayoritariamente por la población, hay indicios para prever que en un futuro no muy lejano la red será un canal utilizado para transmitir un buen número de iniciativas ciudadanas con causa y movilizaciones para incidir en determinados organismos (SÁNCHES, 2007, p. 149).

Por outro lado, a literatura especializada no assunto participação política já diagnosticou que a participação é uma atividade heterogênea, dado que os cidadãos participam politicamente de formas e em níveis diferentes: alguns são muito ativos, outros se comportam casualmente e uma boa parcela não participa ou participa infimamente. Estima-se que $10 \%$ de uma população é regular e ativamente engajada em questões políticas, ao passo que $60 \%$ é vista como participantes eventuais (eleições, plebiscitos, protestos esporádicos) e 
$30 \%$ é tida como apática, pois não participa e não se interessa por política (ANDUIZA; BOSCH, 2007, p. 31).

Essa perspectiva é similarmente reproduzida na internet, notadamente em relação a participação/contribuição virtual (nos softwares abertos - open source -) e política. Sob a epitetada "lei de potência" ou "lei dos 1/10/100", avalia-se que uma fração mínima dos usuários da internet são ativamente participativos e efetivamente contributivos, uma minoria participa regularmente, mas contribui sem ações decisivas, e o grande público de usuários apenas usufrui dos resultados sem levar qualquer contribuição significativa (CARDON, 2012, p. 14). Daí que, não obstante entenda-se a internet como um cenário inovador e fomentador de oportunidades - inclusive políticas - que penetra nas camadas sociais com considerável profundidade e facilidade, não se pode ser ingênuo de crer que ela, apenas por ela, possui força suficiente para alterar os traços políticos (atitude, comportamento, personalidade política) de uma pessoa (representante ou representado) ou sociedade (SÁNCHES, 2007, p. 142).

De qualquer sorte, a ciberparticipação é considerada uma forma de participação política e, enquanto tal, pode gozar dos mesmas consequências positivas que as participações políticas tradicionais, dentre as quais o incremento da confiança interpessoal, o aumento das habilidades cívicas, da atitudes de cooperação e da eficácia política, bem como, em termos de decisão política, a majoração dos níveis de legitimidade e aceitação (ANDUIZA; BOSCH, 2007, p. 56-59). Perceba-se, portanto, que a sugestão de crowdfunding na definição de problemas a serem enfrentados ou não através de políticas públicas possui o mérito de, de um lado, fortalecer a participação política e cidadã e, de outro lado, viabilizar uma plataforma referencial e reflexiva aos formatadores de políticas públicas e a sociedade em geral.

\section{CONCLUSÃO}

A elaboração de uma política pública é precedida pela identificação de um problema social e pela sua qualificação como problema público. Essa qualificação ocorre através de um ato político que, em máximo resumo, o insere na agenda política, reconhecendo o problema social como oportunamente relevante para ser tratado via política pública. Essa qualificação efetivamente se dá em um cenário complexo que envolve atores, pressões, recursos e interesses diferentes em regime de concorrência. Há defensores de que a agenda política 
apenas acontece, tendo em conta que é o resultado do alinhamento de significantes que, originalmente, estavam em desordem no cenário político.

Contudo, essa perspectiva apesar de ser aceita com alguma passividade, guarda em si uma medida incerta de fatalismo (ao aceitar/aguardar a boa/má vontade política ou a ocorrência de pressões/interesses circunstanciais) e de discricionariedade (no sentido de falta de controle da vontade, no caso, política). É comum (ao menos no Brasil) a falta de dados aferíveis e controláveis nas decisões políticas que julgam porque um problema é mais importante que outro e quais foram os fatores que conduziram a eleger/incluir um problema e não outro.

É a partir desta constatação que se projetou uma alternativa paralela ao modo clássico de decisão acerca dos problemas da agenda política baseada nos fundamentos do crowdfunding e diante da internet como nicho de participação política. A proposta, ademais, conjuga em si o reconhecimento da tendência crescente pela utilização do e-gov, das formas de ciberparticipação e as orientações contemporâneas acerca da democratização dos canais do Estado e do agir cooperativo entre sociedade civil e Estado.

A proposta em si, em resumo bastante superficial, consiste na criação de uma plataforma virtual, ao estilo das existentes de crowdfunding, a fim de que pessoas ou grupos comuns pudessem, sem a necessidade de um complexo movimento, publicar seus problemas/ideias para eventuais políticas públicas. Essas postagens poderiam ser objeto de avaliação, colaboração ou críticas de outras pessoas e quando atingissem um número considerável ou suficiente seria encaminhada aos poderes Executivo ou Legislativo a fim de ou servir como norte referencial e reflexivo para a elaboração de políticas; ou funcionar como que, dado o grande apoio angariado na plataforma, devesse ser obrigatoriamente avaliado e fundamentadamente respondido.

Perceba-se, portanto, que a sugestão de crowdfunding na definição de problemas a serem enfrentados ou não através de políticas públicas possui o mérito de, de um lado, fortalecer a participação política e cidadã e, de outro lado, viabilizar uma plataforma referencial e reflexiva aos formatadores de políticas públicas e a sociedade em geral. Apesar das limitações que as iniciativas políticas via internet possuem, isso não deve significar razão determinante para se abandonar ou menosprezar tais empreendimentos; pelo contrário, como no mito de Sísifo, é justamente por esse tipo de ação ainda não ter alcançado todo potencial que possui na esfera política é que se deve continuar a trabalhar nela. 


\section{REFERÊNCIAS}

ANDUIZA, Eva; BOSCH, Agustí. Comportamento político y electoral. 2. ed. Barcelona: Ariel, 2007.

ARAÚJO, Cláudia da Luz Brant de; MAIA, Luiz Cláudio Gomes. Gestão pública e governo eletrônico: estudo sobre sítios institucionais de prefeituras no Estado de Minas Gerais. In: Democracia Digital e Governo Eletrônico, Florianópolis, nº 10, p. 76-103, 2014.

ASCAVA, Lívia. Criar novas formas de participação: desafio na pauta da \#ArenaNETmundial. 2014. Disponível em: < http://gabinetedigital.rs.gov.br/>. Acesso em: 10 jul. 2014.

AUGUSTO, Luís Gustavo Henrique. "www.edemocracia.camara.gov.br" e o processo legislativo participativo. In: CONPEDI/UFSC (Orgs): ROVER, Aires José. CELLA, José Renato Gaziero. AYUDA, Fernando Galindo (Coords). Direito e novas tecnologias: XXIII encontro nacional do Conpedi. Florianópolis: Conpedi, 2014. Disponível em: <http://www.conpedi.org.br/>. Acesso em: 10 jul. 2014.

BRUGUÉ, Joaquim; GALLEGO, Raquel. ¿Una administración pública democrática? In: FONT, Joan (Coord.) Ciudadanos y decisiones públicas. Barcelona: Ariel, p. 43-58, 2007.

CAMPI, Monica. Celular é principal meio de acesso à internet no Brasil. 2013. Disponível em: <http://info.abril.com.br/>. Acesso em: 10 jul. 2014.

CANOTILHO, José Joaquim Gomes. O Estado adjetivado e a teoria da Constituição. In: Revista da Procuradoria Geral do Estado. v. 25, $\mathrm{n}^{\circ}$ 56, 2002, p. 25-40. Porto Alegre, Procuradoria-Geral do Estado do Rio Grande do Sul.

CARDON, Dominique. A democracia internet: promessas e limites. Trad. Nina Vicent e Tiago Coutinho. Rio de Janeiro: Forense Universitária, 2012.

CARRILLO, Irma Leticia Elias. The EU presidency agenda for antiterrorism: a multiple streams analysis. 2007. Disponível em: <http://purl.utwente.nl/essays/58034>. Acesso em: 01 jul. 2014.

CASTOR, Belmiro Valverde Jobin. Progressos na capacidade cognitiva e o poder de arbítrio do deliberador. In: HEIDEMANN, Francisco G.; SALM, José Francisco (Orgs.). Políticas públicas e desenvolvimento: bases epitemológicas e modelos de análise. Brasília: UnB, 2009 , p. 250-257.

CETIC (Centro de Estudos sobre Tecnologia da Informação e da Comunicação). TIC domicílios e usuários 2013. Acesso às Tecnologias da Informação e da Comunicação (TIC). 2013a. Disponível em: <http://www.cetic.br/usuarios/tic/2013/index.htm>. Acesso em: 12 jul. 2014. 
CETIC (Centro de Estudos sobre Tecnologia da Informação e da Comunicação). TIC domicílios e usuários 2013. Governo Eletrônico. 2013b. Disponível em: <http://www.cetic.br/usuarios/tic/2013/index.htm>. Acesso em: 12 jul. 2014.

COHEN, Michael D; MARCH, James G; OLSEN, Johan P. A garbage can model of organization choice. In: Administrative Science Quarterly, vol. 17, n. 1, 1972, p. 1-25.

DYE, Thomas R. Mapeamento dos modelos de análise de políticas públicas. In: HEIDEMANN, Francisco G.; SALM, José Francisco (Orgs.). Políticas públicas e desenvolvimento: bases epitemológicas e modelos de análise. Brasília: UnB, 2009, p. 99-132.

DYE, Thomas R. Understanding public policy. 12. ed. New Jersey: Pearson, 2008.

ETZIONI, Amitai. Reexame da estratégia mista de decisão. In: HEIDEMANN, Francisco G.; SALM, José Francisco (Orgs.). Políticas públicas e desenvolvimento: bases epitemológicas e modelos de análise. Brasília: UnB, 2009, p. 233-249.

FRAGOSO, Suely; MALDONADO, Alberto Efendy. Panorama da internet na América Latina. In: FRAGOSO, Suely; MALDONADO, Alberto Efendy (Orgs.) A internet na América Latina. Porto Alegre: Sulina, 2009, p. 13-39.

GOMES, Wilson. A democracia digital e o problema da participação civil na decisão política. In: Revista Fronteiras: estudos midiáticos, VII, Set/Dez, p. 214-222, 2005.

HERMANY, Ricardo; FRANTZ, Diogo. A modernização da gestão pública municipal: uma perspectiva a partir das audiências públicas. In: REIS, Jorge Renato dos; Leal, Rogério Gesta (Orgs.). Direitos sociais e políticas públicas: desafios contemporâneos. Tomo 10. Santa Cruz do Sul: Edunisc, 2010, p. 3233-3254.

HOWLETT, Michael; RAMESH, M.; PERL, Anthony. Política pública: seus ciclos e subsistemas: uma abordagem integradora. Rio de Janeiro: Elsevier, 2013.

IBOPE. Número de pessoas com acesso à internet no Brasil chega a 105 milhões. 2013. Disponível em: <http://www.ibope.com.br/>. Acesso em: 10 jul. 2014.

KINGDON, J. W. Agendas, Alternatives, and Public Policies. New York: HarperCollins College Publishers, 1995.

LEMOS, André; LÉVY, Pierre. O futuro da internet: em direção a uma ciberdemocracia planetária. São Paulo: Paulus, 2010.

MINISTÉRIO DO PLANEJAMENTO, ORÇAMENTO E GESTÃO. Gov.br: histórico. S/d.

PARSONS DESIS LAB. Gov Innovation Labs: Constellation 1.0. Disponível em: <http://nyc.pubcollab.org/>. Acesso em: 12 jul. 2014. 
PINTO, Isabela Cardoso de Matos. Mudanças nas políticas públicas: a perspectiva do ciclo de política. In: Revista Políticas Públicas. São Luis, v. 12, n. 1, jan./jun. 2008, p. 27-36.

RIBEIRO, Carla Andrea; ANDRADE, Maria Eugênia Albino. Governança informacional como sustentação das ações de combate à corrupção. In: Anais do XVIII Concurso del CLAD sobre Reforma del Estado y Modernización de la Administración Pública. 2005.

RODRIGUES, Marta M. Assumpção. Políticas Públicas. São Paulo: Publifolha, 2010.

SÁNCHES, Jordi. Internet como instrumento de participación. In: FONT, Joan (Coord.) Ciudadanos y decisiones públicas. Barcelona: Ariel, p. 141-152, 2007.

SCHMIDT, João Pedro. Para entender as políticas públicas: aspectos conceituais e metodológicos. In: REIS, Jorge Renato; LEAL, Rogério Gesta (Org.). Direitos Sociais e Políticas Públicas: desafios contemporâneos. Tomo 8. Santa Cruz do Sul: EDUNISC, 2008, p. 2307-2333.

SCHMIDT, João Pedro; MENEGAZZI, Piero Rosa. Bases teóricas para o desenvolvimento de política públicas sobre a informação ambiental. In: REIS, Jorge Renato dos; LEAL, Rogério Gesta (Orgs.). Direitos sociais e políticas públicas: desafios contemporâneos. Tomo 10. Santa Cruz do Sul: Edunisc, 2010, p. 3123-3158.

SOUZA, Celina. Políticas Públicas: uma revisão da literatura. In: Sociologias (Porto Alegre), ano $8, \mathrm{n}^{\circ} 16$, jul/dez 2006, p. 20-45.

SUBIRATS, Joan. et al. Análisis y gestión de políticas públicas. Barcelona: Planeta, 2012. 